\title{
Forget the Desk Job: Current Roles and Responsibilities in Entry-Level Reference Job Advertisements
}

\section{Robert Detmering and Claudene Sproles}

\begin{abstract}
This study examines the evolving roles and responsibilities of entry-level academic reference positions, as stated in recent job advertisements posted on the American Library Association's JobLIST Web site and other sources. Findings from a content analysis of these advertisements indicate that current entry-level reference positions in academic libraries incorporate a strikingly diverse and complex range of responsibilities. The study provides valuable insight into the expectations and priorities of hiring institutions in regard to entry-level reference work, offering a broad perspective on the reference job environment to library science students, first-time job seekers, and libraries seeking to recruit entrylevel candidates.
\end{abstract}

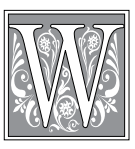

riting about her search for a professional librarian position as an entry-level candidate, Theresa Bruno emphasizes the "misery" of this difficult and often disappointing process. ${ }^{1}$ As one new job seeker explains, "You can't get a librarian position because you don't have experience and you can't get experience unless you have a librarian position." ${ }^{2}$ Not yet fully integrated into the culture of professional librarianship and lacking significant experience, many entry-level candidates, like Bruno, face a challenging job market. While the potential difficulties of the entry-level market have been debated, ${ }^{3}$ the initial job search remains a daunting prospect for many recent graduates of library science programs. At the same time, as library services continue to evolve, hiring institutions expect successful candidates to take on many new responsibilities and learn new skills. This constantly changing environment leads to additional pressure and uncertainty for entry-level job seekers.

Addressing the concerns associated with entry-level job seeking in a time of rapid change, this study focuses on the roles and responsibilities of entry-level academic reference positions as stated in recent job advertisements. As with other areas of librarianship, reference services in academic libraries have evolved in response to emerging technologies and evolving user dynamics. ${ }^{4}$ Many academic libraries are moving away from staffing a traditional reference desk in favor of 
multifaceted and collaborative learning spaces, such as an information commons. These areas merge several services into one location, decreasing the importance of a traditional desk. Coupled with changes in physical space, academic reference librarians have adopted many new roles, such as serving as "embedded librarians" in particular classes, offering electronic outreach services such as chat and texting, participating in virtual and social networking environments, collaborating with faculty on information literacy initiatives, and much more. ${ }^{5}$ As a result, beginning reference librarians must be prepared for a diverse range of responsibilities, and hiring institutions must carefully consider their priorities for reference positions.

This study of job advertisements attempts to categorize a complex job environment as well as providing insight into how academic libraries currently envision the role of the reference librarian within the library itself and the larger campus community. The central questions for the study include:

1. What are the primary duties and responsibilities of an entry-level academic reference librarian?

2. What trends are emerging in entrylevel academic reference work?

3. What skills will successful entrylevel candidates need to meet the expectations defined by hiring institutions in recent job advertisements?

Results should be of interest to those currently enrolled in library science programs, first-time job seekers, libraries seeking to recruit entry-level candidates, and anyone interested in the evolving nature of reference librarianship. Although a few content analyses of job advertisements have discussed requirements to obtain an entry-level reference position or categorized listed job duties in advertisements, no study has researched the stated duties of entry-level positions in reference. Thus, this study provides unique value as a snapshot of current reference responsibilities at the entry level.

\section{Literature Review}

Of the many studies that have focused on job advertisement analysis, a few have explored trends in job duties. In 2001, Beverly Lynch and Kimberley Robles Smith reviewed public and technical service job advertisements in academic settings to ascertain how the nature of positions changed from 1973 to $1998 .{ }^{6}$ For reference positions, they found in the beginning no mention of instruction duties. By 1998, however, such duties were pervasive in all the ads surveyed. They also discovered emerging requirements in all positions for technology skills and behavioral attributes such as effective communication. Their findings also indicated a new demand for specialized skill sets.

Karen Croneis and Pat Henderson examined job advertisements with the word "digital" or "electronic" in the title published in College and Research Libraries News (CERL News) from 1990 to $2000 .^{7}$ Analyzing various aspects of the advertisements, including position title, functional area, institution type, and job responsibilities, they found that positions with responsibilities in the digital or electronic realm increased significantly during the period, moving beyond public services to include many other functional areas of the library and incorporating both traditional and new job duties for librarians.

Lori Goetsch traced the evolving nature of reference, subject, and systems librarian positions by studying a selection of CERL News job advertisements from 1995, 2000, and 2005. ${ }^{8}$ Her analysis of position titles as well as job responsibilities and requirements indicated that the role of technology in the profession had become increasingly important over time. Goetsch delineates four primary areas of responsibility for professional librarians in the 21st century: "consulting services; information lifecycle management; collaborative print and electronic collection building; and information mediation and interpretation." ${ }^{9}$ Recently, John Meier examined fifty-three job advertisements 
for science and engineering librarians posted on the American Library Association (ALA) JobLIST Web site in 2008 and $2009 .{ }^{10} \mathrm{He}$ scrutinized job duties to assess the increase in tasks assigned to these librarians based on numbers found in other studies. Meier discovered a marked increase in the number of duties required of the positions, while the actual number of open positions decreased.

Hanrong Wang, Yingqi Tang, and Carley Knight scanned reference job ads posted in CERL News from 1966 to 2009 to track the historical development of the profession. ${ }^{11}$ Examining reference positions, they calculated the number of open positions, educational background, duties and responsibilities of the position, and variations in job titles. Over the years, an enormous growth in reference positions occurred. Analysis revealed that, in addition to standard duties of "reference, instruction, and collection development," by the late 1990s, "[W]eb design, library systems, distance education support, and digitizing" emerged as common responsibilities for reference librarians. ${ }^{12}$

Entry-level librarianship, too, has been discussed in relation to job ad analysis in a variety of studies over the years. David Reser and Anita Schuneman examined more than 1,000 job ads from 1988 to investigate differences between public and technical services librarians. ${ }^{13}$ For their study, they defined entry-level as "(1) had no work experience mentioned in the advertisement; (2) had a statement specifying that no experience was necessary; or (3) were labeled 'entry level.'"14 They found that 18 percent of positions listed could be classified as entry-level, and reference posted more entry-level positions than technical services. They concluded that employers should relax requirements for entry-level catalogers to encourage more LIS students to seek careers in technical services. In a follow-up to Reser and Schuneman's article, Penny Beile and Megan Adams expanded the analysis to include systems librarians. ${ }^{15}$ They used the same criteria as Reser and
Schuneman to determine entry-level positions and ultimately classified 20 percent of advertised positions as entry-level. Overall, their research determined that librarian positions were requiring more specialization, and they identified a trend toward accepting non-MLS professionals for librarian positions.

In 2004, Claudene Sproles and David Ratledge looked at academic entrylevel jobs over a period of twenty years to determine if entry-level jobs were decreasing over time. ${ }^{16}$ They found that the percentage of entry-level positions remained relatively constant, but the requirements for these positions increased dramatically. They determined that actual work experience is a virtual necessity to secure an open position. Using the criteria set forth by Sproles and Ratledge, Robert Reeves and Trudi Bellardo Hahn studied the requirements for entry-level positions in public, special, and academic libraries during a period between 2006 and 2009. ${ }^{17}$ Results showed that the vast majority of entry-level jobs were in the academic setting. Entry-level positions were increasing, along with the requirements to obtain these positions. Personal attributes such as communication and collaboration skills were valued along with experience. Confirming the findings of Sproles and Ratledge, Reeves and Hahn argued that new graduates realistically need to gain practical experience in the field before obtaining their first professional jobs.

\section{Methodology}

As previous studies have indicated, it is no longer possible to obtain an adequate sample of print advertisements, as most employers prefer to post ads online for a limited time. Rachel Applegate notes that "researchers interested in more than a onetime snapshot must create their own archives by preserving identified job ads in a personal repository" to create an adequate sample. ${ }^{18}$ To collect a representative archive of entry-level academic reference job ads for this study, several online sources were monitored 
from January to December 2010. The Web sites ALA JobLIST and LISjobs.com were monitored weekly, in addition to the popular reference listserv, LIBREF-L (hosted by Kent State University), and the popular information literacy and library instruction listserv, ILI-L (hosted by the American Library Association and the Association of College and Research Libraries). Institutional Web sites were consulted for the complete ad if only a partial description was provided in the original posting.

From the ads gathered, stated job requirements were analyzed to determine if the position was entry-level. Using the criteria originally refined by Sproles and Ratledge and later employed by Reeves and Hahn, ads were categorized as entrylevel if they met the following criteria:

- Ad says "entry-level;"

- No mention of required professional experience;

- No experience or duties impossible for entry-level librarians to gain.

While subjective, the third criterion allows for consideration of paraprofessional or other types of work experience obtained before entering the profession. Ads that implied a requirement for professional experience, such as those involving extensive administrative duties or requiring progressively responsible experience, were excluded from the sample. For ads to be included in the study, they needed to be full-time, permanent positions. Community college positions, as well as positions outside the United States, were excluded from the study.

Ads were classified as reference positions if the primary job duties were in a reference department. Ads that required work on the reference desk, but primary job responsibilities were clearly in another area, such as collection development or Web services, were excluded. At the end of the year, 385 entry-level job ads were gathered. Of these, 192 (49.9\%) entry-level ads were identified as reference positions. While this sample is not necessarily comprehensive, it provides a significant and representative sample of entry-level job postings in reference at the national level.

The stated job duties listed in the ads were then assigned to broad categories. As job ads often incorporate a wide variety of responsibilities, these responsibilities often overlapped and were included in more than one category. In certain instances, the authors collectively made subjective judgment calls in assigning responsibilities to particular categories because, inevitably, different libraries employ different terminology to describe job duties. The following types of duties, which emerged during the coding process, reflect distinct areas of responsibility included in the sample. The duties were also divided into three larger categories: traditional duties, emerging duties, and other duties. Traditional duties encompassed tasks normally associated with a reference department:

- The Reference category includes the provision of reference or research assistance in some form (in person, by phone, by e-mail, or any other form of communication) to students, faculty, or other user groups. This includes general assistance in multiple subject areas as well as subject-specific assistance. This category also includes the provision of individual or group research consultations.

- The Information Literacy and Library Instruction category includes the development and delivery of library instruction or information literacy sessions or courses. This includes both traditional classroom teaching and online instruction. While in-person or online reference assistance often incorporates teaching, for the purposes of this study, Information Literacy and Library Instruction is a distinct category comprising only those duties and responsibilities related to the formal provision of instruction in a classroom or online setting.

- The Departmental Liaison category includes responsibilities involving communication or consultation with specific academic departments. The liaison role often requires the librarian 
to cultivate and maintain close ties with faculty members or students in particular departments.

- The Collection Development category includes activities related to building and maintaining library collections in general or specific subject areas. This includes the selection of resources in all formats.

- The Supervision/Management category describes duties related to supervising and/or training staff members, student workers, or other librarians. This category also entails various defined leadership roles or administrative functions within the library organization, such as the supervision of a particular department or unit. Tasks such as creating schedules or evaluating employee performance are included as well.

Emerging duties were defined as responsibilities not historically associated with reference work or newer tasks that have started to appear in ads:

- The Promotion/Marketing category relates to promoting or marketing library services to external groups. This may include hosting library-related events, making presentations on or off campus, and/or developing brochures or other promotional materials. This category defines promotion in a broad sense, beyond the more limited or narrowly focused role of the departmental liaison.

- The Technology category includes activities that expressly involve the use of computer or computer-related technology. This may include authoring Webbased content, creating online tutorials, incorporating emerging technologies into library services, digitizing materials, or other responsibilities. While technology of this nature certainly plays a role in almost all aspects of current library jobs, this category focuses on duties the hiring institution has defined as having a specific technology component and that will likely require a certain set of specialized skills to carry out effectively.

- The Planning/Implementation category includes activities that require direct participation in the design, development, and/or implementation of various programs, services, and goals. This differs from the supervision/management category as it involves the coordination of initiatives rather than the direct supervision of personnel. While many job responsibilities involve planning or implementation to varying degrees, this category only includes tasks that expressly mention participation in some type of developmental process.

- The Governance category involves participation in library or campuswide committees, task forces, or governing bodies.

- The Assessment category involves assessing or evaluating library programs and/or services. Job ads rarely mention specific assessment measures or tools, such as user surveys, but they often include assessment as a general responsibility.

- The Scholarly Communication category includes activities related to scholarly communication, data sharing, digital publishing, or similar areas.

Other duties included items necessary for promotion and tenure, or miscellaneous items that did not fit into other categories.

- The Professional Activity category includes responsibilities related to professional organizations beyond the purview of an individual library or institution. This category also includes scholarly activities, including publishing. Responsibilities in this category are often associated with promotion and tenure at certain institutions.

- The Other Duties category includes unique or uncommon reference duties (such as cataloging or circulation responsibilities). In addition, this category includes tasks defined by ambiguous statements such as "other duties as assigned."

\section{Analysis and Discussion}

Roughly half (49.9\%) of entry-level jobs found were reference positions. This was 


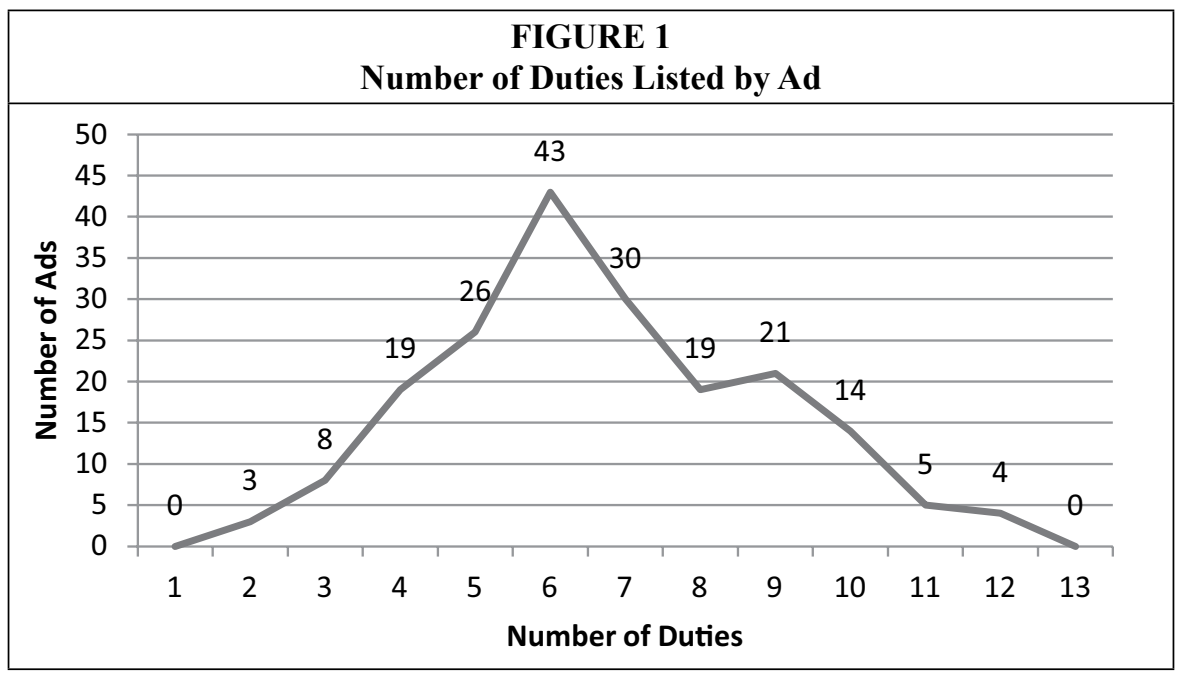

down from Sproles and Ratledge's findings of 64 percent in 2002. ${ }^{19}$ This finding suggests the transfer of reference positions to other areas, such as electronic resources or an information commons. Most positions evaluated required several varying types of job duties. Analysis revealed an average of almost seven separate categories of responsibility per ad (see figure 1). A total of 70.8 percent of ads included duties in six or more categories, and 22.9 percent included duties in nine or more categories. This underscores Meier's assertion that job duties continue to increase. ${ }^{20}$ Entry-level candidates will be expected to perform a wide variety of tasks on the job, many of which may not be directly related to their initial training or knowledge.

Almost 97 percent of the ads collected for this study listed responsibilities in the area of information literacy and library instruction. See table 1 and figure 2 for the breakdown of percentages by category. Indeed, formal instructional duties appeared almost as often as reference service duties (which appeared in 98.9 percent of the ads) and were often emphasized as core responsibilities, either through prominent placement in a position title (such as "Instruction and Research Services Librarian" or "Reference and Instruction Librarian") or through extended statements regarding teaching, pedagogy, and/or instructional design. Thus, from an institutional perspec- 


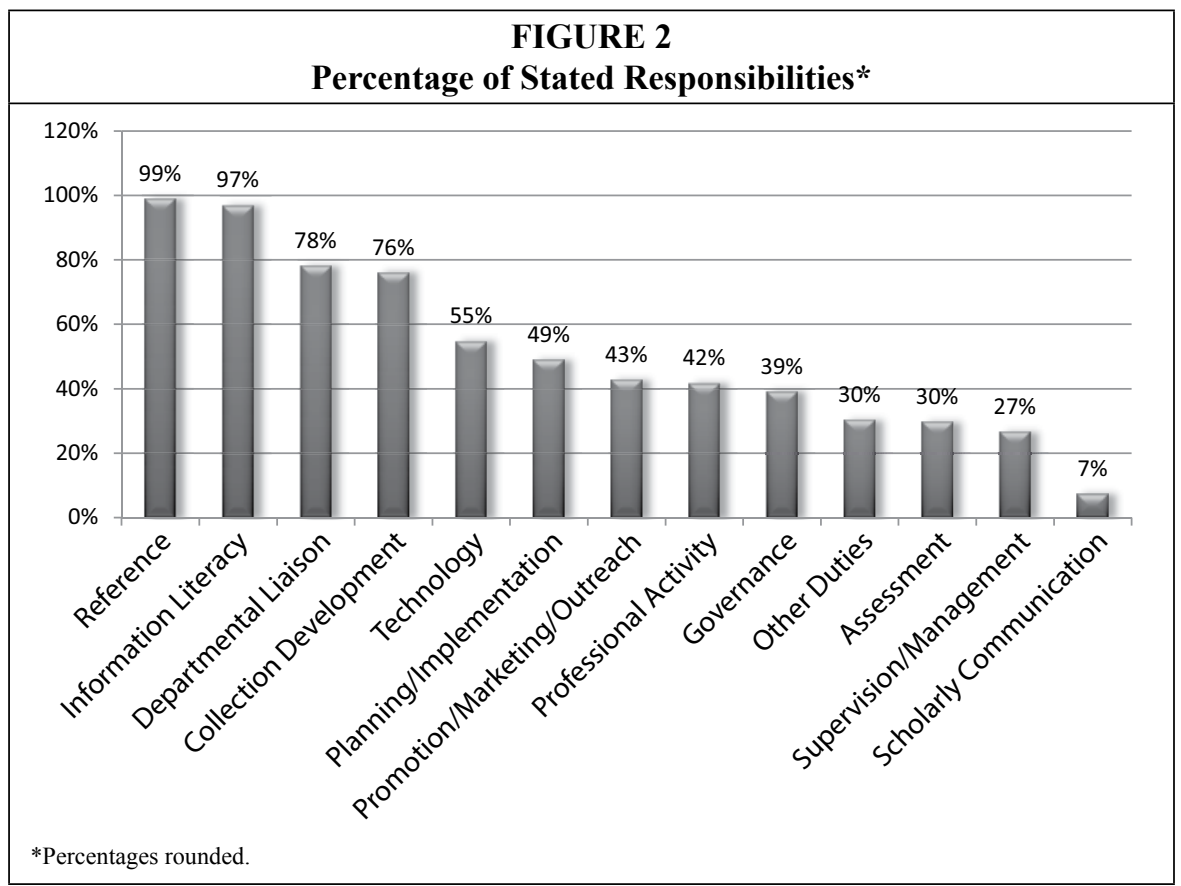

tive, while reference and instruction may not be synonymous, they are essentially inseparable. In contrast, less than a decade ago, Sproles and Ratledge reported that only 39 percent of entry-level reference jobs required knowledge of bibliographic instruction. ${ }^{21}$ While knowledge differs from duty, it nevertheless illustrates the importance of information literacy. Given this huge jump in a relatively short period, it is clear that an entry-level job candidate interested in academic reference should expect that teaching will be mandatory in any position she or he obtains and, in most cases, defined as a central component of the position.

The high frequency of traditional collection development $(76.0 \%)$ and departmental liaison $(78.1 \%)$ responsibilities in the sample (see figure 3 ) were an

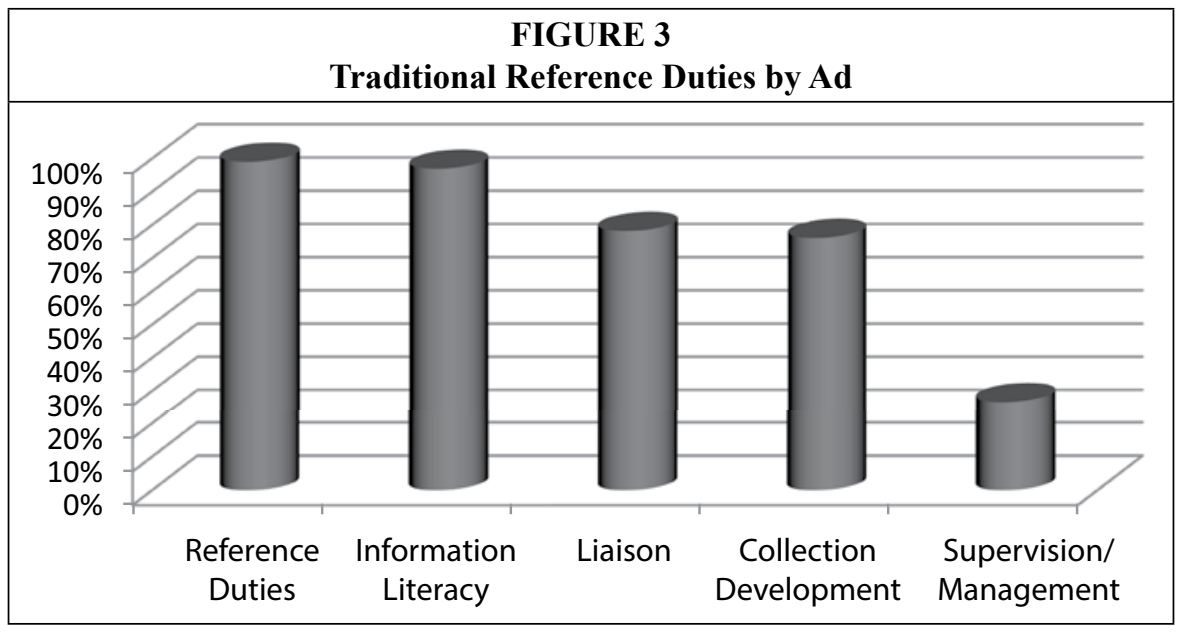


expected finding in light of Wang, Tang, and Knight's study. ${ }^{22}$ Trends noted in the ads included new responsibilities for content management such as curating data in various subject areas, managing electronic subscriptions, and participating in vendor relations. The widespread inclusion of departmental liaison duties further demonstrates the need for entrylevel reference librarians to gain practical experience with collection development, since these librarians will often be required to communicate and collaborate with teaching faculty regarding library collections. Another emerging component of liaison work is increased classroom collaboration with faculty, reiterating the need for effective instruction skills in reference work.

Numerous ads (42.7\%) referred to emerging responsibilities in promotion, marketing, and/or outreach to various groups, both on and off campus (see figure 4). Considering this number in light of the large percentage of ads that included liaison responsibilities, the findings of this study agree with Wang, Tang, and Knight's assertion that "[1]iaison and outreach services have become one of the core duties of reference librarianship." ${ }^{23}$ These responsibilities reflect a new consultant role for librarians away from the reference desk, and they also support Goetsch's findings that "market- ing and public relations specialists" are increasingly valued by libraries. ${ }^{24}$ Indeed, the sample for this study indicates that entry-level reference librarians will often direct their energies externally, not only in terms of providing an expert service but also in terms of promoting or selling the value of that service. In some positions, the ability to engage in an effective reference interview or teach an information literacy session may be just as important as the ability to market and promote these and other library services. The difference between these two related reference roles (provision of service and promotion of service) is not trivial. The ever-increasing number of publications on library marketing attests to the significance of this distinctive role in the contemporary practice of librarianship. ${ }^{25}$ Therefore, entry-level reference librarians need to be able to develop a strong understanding of the needs of faculty, administrators, and other stakeholders in the academic environment and to reach out to these groups effectively.

More than one quarter $(26.6 \%)$ of the collected ads included responsibilities in the area of supervision and/or management. Occasionally, hiring institutions defined a specific supervisory role for the position (such as leading a particular department or team); however, in most instances, institutions simply indicated

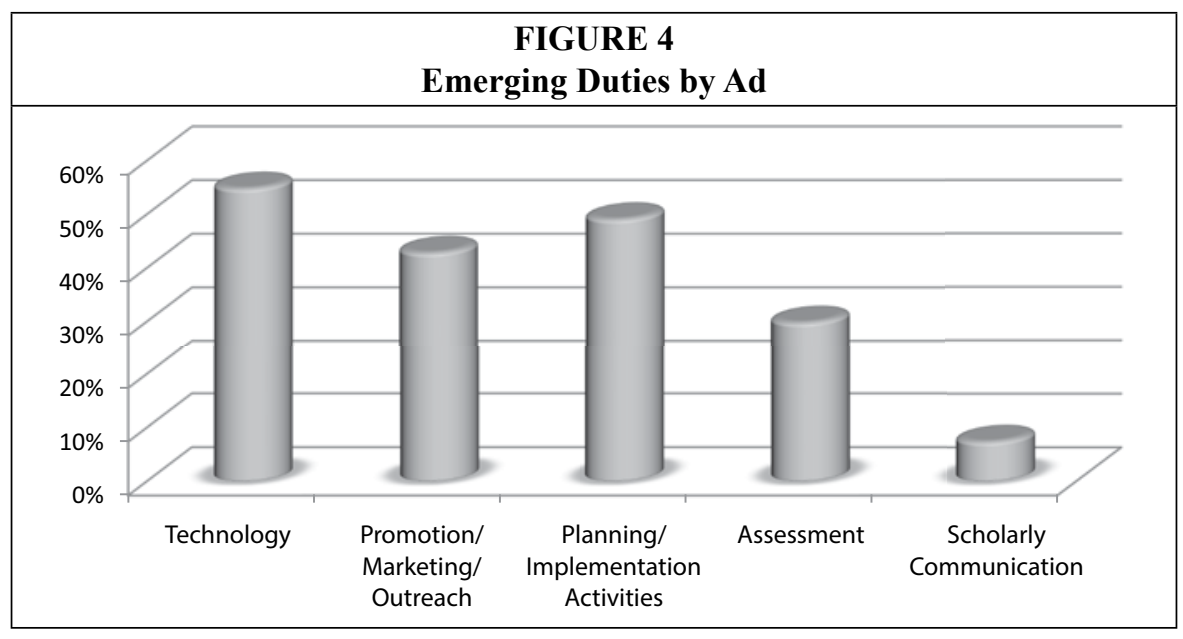


that the open position would require supervision of staff or student workers without additional explanation. In their study of entry-level ads, Reeves and Hahn found that only 13.6 percent of ads required supervisory experience, ${ }^{26}$ and Sproles and Ratledge found that the requirement for supervisory experience in entry-level ads decreased over a twentyyear period. ${ }^{27}$ The findings of the present study likewise suggest that the majority of hiring institutions do not associate supervision with entry-level positions, as it is seldom included among listed job responsibilities. Additionally, the small number of ads requiring supervision of personnel indicates mergers of positions and services throughout academic libraries, concentrating supervision among a few key personnel.

On the other hand, nearly half of the job ads collected for this study (49.0\%) included activities and responsibilities in project planning and implementation. While these duties do not necessarily involve direct supervision or management, they would likely require active participation and leadership within teams or work groups. In this sense, planning and implementation maintain a clear relationship with supervision and management, in that the skills associated with both categories are similar. Also, many of the aforementioned reference duties, such as collection development or instructional design, involve management, even if the word itself does not appear in a particular ad.

As a result, regardless of whether an entry-level position incorporates an explicit management role or includes duties in planning or implementation, successful job candidates will almost certainly be expected to perform effectively in these areas. As Joan Giesecke and Beth McNeil point out, team-based organizational approaches that encourage a "culture of cooperation" have become prevalent in libraries. ${ }^{28}$ The increasing emphasis on teams and shared leadership roles suggests that entry-level candidates should be ready to serve as leaders, at least on a limited basis in relation to various reference projects and tasks.

Studies by Lynch and Smith and Wang, Tang, and Knight emphasize the increasing importance of technology skills in librarian positions. ${ }^{29}$ Of the job ads collected for this study, 54.7 percent included specific responsibilities with a technological focus. Jobs may require the development of Web-based reference materials (such as tutorials or subject guides) or more substantial responsibilities in Web management and/ or technical support. Additionally, many ads refer to responsibilities involving the integration of emerging technologies such as Web 2.0 tools into reference and instructional services, including the use of technology in embedded librarian roles. Thus, the findings from this study reiterate the central role of new and emerging technologies in academic librarianship, as well as the need for those entering the profession to learn specialized skills in these areas. Though not necessarily surprising, the emphasis on technology-related duties in many ads suggests that reference librarians also serve as technology specialists, highlighting once again the diversity and potential complexity of reference work.

As numerous publications indicate, assessment has emerged as a significant topic of discussion in the literature on academic libraries. ${ }^{30}$ In their introduction to a recent special issue of Library Quarterly focusing on the 2010 Library Assessment Conference, Martha Kyrillidou, Steve Hiller, and Jim Self note that the assessment of library services has become "integral" to the practice of librarianship; they argue that "the twenty-first century library cannot survive unless it develops and uses assessment techniques to ensure that we remain vital and necessary to the communities we serve." ${ }^{31}$ With academic libraries increasingly being held accountable for measuring their impact on learning, ${ }^{32}$ it stands to reason that as- 
sessment would emerge as a specifically articulated area of responsibility in job ads. The analysis revealed 29.7 percent of the ads collected for this study include responsibilities for assessing or evaluating library programs, services, and/or collections. In most cases, the word "assess" appears in a list of verbs associated with particular services, as in "plan, develop, maintain, and assess innovative instructional and outreach programs." At times, language related to assessment remains vague, as in the phrase "assessment of current practices." Nevertheless, this set of ads reflects the growing emphasis on assessment in the field. This push, which seems to be strengthening in reaction to institutional and cultural pressure toward accountability, suggests that the number of entry-level positions including assessment responsibilities will continue to rise in the coming years. Assessment is not merely the task of library administration but a shared responsibility in which entry-level librarians should be prepared to participate.

While not pervasive, scholarly communication $(7.3 \%$ of ads) emerged as another significant trend, particularly in science subject specialist positions. This duty requires collection development and management skills, along with strong subject-based knowledge. Entry-level librarians may be expected to provide some measure of expertise and training in relation to data-sharing projects, open access initiatives, digital repositories, or related efforts. More than a third $(39.1 \%)$ of the ads specifically addressed participation in shared governance. This percentage reflects academic librarianship's strong association with faculty status. In 2006, Jeanie Welch's survey of academic librarians at Doctoral/Research Intensive institutions found that 72.2 percent of positions have faculty status and that 86.5 percent were eligible to serve on campus committees. ${ }^{33}$ These findings indicate that entry-level reference librarians may be expected to take on leadership roles within their institutions by serving on library or campus governing bodies (such as a faculty senate). Also strongly correlated with faculty status, professional activity appeared in 41.7 percent of the collected ads. New graduates will often be expected to participate in professional library organizations and engage in scholarly publishing in the field. The degree to which a new reference librarian should participate in these activities is rarely defined in job ads and will likely vary from institution to institution.

\section{Limitations of Study and Suggestions for Future Research}

As Hong Xu points out in an older study of reference and cataloging job ads, research of this nature can involve "too many uncontrollable variables to support far-reaching conclusions." ${ }^{34}$ With Xu's caveat in mind, this study primarily attempts to offer a broad perspective on the current responsibilities of entry-level academic reference librarians; however, certain limitations remain. This study does not address potential variations in job responsibilities based on unique institutional characteristics such as collection size, staff size, or institution type (for example: Carnegie classification or membership in the Association of Research Libraries). Given this limitation, future research on job trends could explore the impact of institutional characteristics on the nature of reference work at the entry level. Furthermore, because this study provides only a one-year analysis of entry-level trends, a longitudinal analysis is needed to determine which emerging responsibilities are of a lasting nature and which ones are more temporary. However, it should be noted that, due to the limited posting time of job ads on the Web, researchers interested in tracking changes over time would need to create, as Applegate calls it, a "personal repository" of ads. ${ }^{35}$ Still, a longitudinal study would certainly be of great value in understanding larger patterns in relation to the evolving professional responsibilities of academic reference librarians. 


\section{Conclusion}

Overall, the findings revealed that entrylevel reference candidates should be prepared for an extraordinarily diverse range of responsibilities. As such, these responsibilities will likely require potentially very different, albeit related, skill sets. An entry-level reference librarian may serve as a classroom teacher, instructional designer, research assistant, collection specialist, data curator, communications expert, marketing consultant, program supervisor, project manager, Web developer, and/or professional scholar, in addition to other reference tasks. In a few instances, entry-level reference positions include responsibilities in cataloging, circulation, or other areas far outside the traditional realm of a reference department. This concurs with Wang, Tang, and Knight's discovery that many "new duties and responsibilities are added to reference positions" over time. ${ }^{36}$

The primary duties still strongly reflect the traditional duties of reference, instruction, liaison, and collection development. However, more traditional supervision duties are being replaced with project management and implementation skills, which are not traditionally associated with entry-level reference jobs. This finding, coupled with the increased push for marketing and promotion of library services, lends credence to Mark Winston and Gretchen Ebeler Hazlin's argument that library and information science educational programs should emphasize marketing in the teaching of management and leadership skills. ${ }^{37}$

Furthermore, the pervasive combination of reference and information literacy duties underscores the need for entry-level candidates to gain practical teaching experience. This finding supports the assertion, as noted in a study by Sproles, Johnson, and Farison, that library science programs should fully integrate information literacy instruction as a key component of the reference curriculum. ${ }^{38}$ While building and maintaining general and specialized collections remain central to reference work, Joanne Oud's recent survey of new academic librarians suggests that many feel unprepared for these duties. ${ }^{39}$ In Oud's study, "respondents mentioned frequently that they had little training in this area [collection development] in library school and that their on-the-job training was lacking or inadequate." ${ }^{40}$ It would certainly be prudent, then, for library science students interested in reference to seek opportunities to learn about and practice collection development activities, even if such opportunities are limited in scope.

Newer trends highlighted in this study indicate that technology-related skills are being sought. Librarians with skills in electronic data management, data curation, embedded librarianship, electronic publishing, and scholarly communication will be in increasing demand. Candidates need to possess a specialized skill set, display thorough subject knowledge, and stay abreast of current trends in librarianship and their subject disciplines. Based on the expectation that new librarians will be expected to contribute to the profession, new librarians should seek opportunities to be involved in professional organizations as well as opportunities to learn about research methods and publishing in academic librarianship while still enrolled in library school.

Although it is not within the scope of this study to address whether the number and variety of stated responsibilities for entry-level positions are unrealistic or impractical, hiring institutions may want to consider the major priorities for entrylevel positions, as well as the amount of on-the-job training and professional development they will be able to provide for new hires in these positions. If an institution truly wishes to hire an entry-level reference librarian with new ideas and fresh perspectives, then that institution should offer adequate support or mentoring to ensure that the new librarian can succeed in what is, as this study clearly demonstrates, the complex, multifaceted job of reference librarianship. 


\section{Notes}

1. Theresa Bruno, “It Isn't Just Me: A Story of Four Recent Library Science Graduates on the Prowl for Their First Librarian Job," Indiana Libraries 28, no. 2 (2009): 20.

2. Bruno, "It Isn't Just Me," 20.

3. Rachel Holt and Adrienne L. Strock, "The Entry-Level Gap," Library Journal 130, no. 8 (2005); David Conners and Laena McCarthy, "The Jobs Can Be Found," Library Journal 132, no. 14 (2007); Rachel Holt and Adrienne L. Strock, "The Entry-Level Gap, Revisited," Library Journal 132, no. 16 (2007).

4. Sarah K. Steiner and M. Leslie Madden, The Desk and Beyond: Next Generation Reference Services (Chicago: Association of College and Research Libraries, 2008), v-vi.

5. Steiner and Madden, The Desk and Beyond; Diane Zabel, Reference Reborn: Breathing New Life into Public Services Librarianship (Santa Barbara: Libraries Unlimited, 2011).

6. Beverly P. Lynch and Kimberley Robles Smith, "The Changing Nature of Work in Academic Libraries," College \& Research Libraries 62, no. 5 (2001).

7. Karen S. Croneis and Pat Henderson, "Electronic and Digital Librarian Positions: A Content Analysis of Announcements from 1990 through 2000," The Journal of Academic Librarianship 28, no. 4 (2002).

8. Lori A. Goetsch, "Reinventing Our Work: New and Emerging Roles for Academic Librarians," Journal of Library Administration 48, no. 2 (2008).

9. Goetsch, "Reinventing Our Work," 167.

10. John J. Meier, "Are Today's Science and Technology Librarians Being Overtasked? An Analysis of Job Responsibilities in Recent Advertisements on the ALA Joblist Web Site," Science \& Technology Libraries 29, no. 1/2 (2010).

11. Hanrong Wang, Yingqi Tang, and Carley Knight, "Contemporary Development of Academic Reference Librarianship in the United States: A 44-Year Content Analysis," Journal of Academic Librarianship 36, no. 6 (2010).

12. Wang, Tang, and Knight, "Contemporary Development of Academic Reference Librarianship," 493.

13. David W. Reser and Anita P. Schuneman, "The Academic Library Job Market: A Content Analysis Comparing Public and Technical Services," College \& Research Libraries 53, no. 1 (1992).

14. Reser and Schuneman, "The Academic Library Job Market," 53.

15. Penny M. Beile and Megan M. Adams, "Other Duties as Assigned: Emerging Trends in the Academic Library Job Market," College \& Research Libraries 61, no. 4 (2000).

16. Claudene Sproles and David Ratledge, "An Analysis of Entry-Level Librarian Ads Published in American Libraries, 1982-2002," Electronic Journal of Academic E Special Librarianship 5, no. 2/3 (2004).

17. Robert K. Reeves and Trudi Bellardo Hahn, "Job Advertisements for Recent Graduates: Advising, Curriculum, and Job-Seeking Implications," Journal of Education for Library \& Information Science 51, no. 2 (2010).

18. Rachel Applegate, "Job Ads, Jobs, and Researchers: Searching for Valid Sources," Library $\mathcal{E}$ Information Science Research 32, no. 2 (2010): 168.

19. Sproles and Ratledge, "An Analysis of Entry-Level Librarian Ads."

20. Meier, "Are Today's Science and Technology Librarians Being Overtasked?"

21. Sproles and Ratledge, "An Analysis of Entry-Level Librarian Ads."

22. Wang, Tang, and Knight, "Contemporary Development of Academic Reference Librarianship."

23. Wang, Tang, and Knight, "Contemporary Development of Academic Reference Librarianship," 493.

24. Goetsch, "Reinventing Our Work," 179.

25. For example, the American Library Association has published a number of books on marketing academic library services, including Jeannette A. Woodward, Creating the Customer-Driven Academic Library (Chicago: American Library Association, 2009), and Brian Mathews, Marketing Today's Academic Library: A Bold New Approach to Communicating with Students (Chicago: American Library Association, 2009).

26. Reeves and Hahn, "Job Advertisements for Recent Graduates," 116.

27. Sproles and Ratledge, "An Analysis of Entry-Level Librarian Ads."

28. Joan Giesecke and Beth McNeil, Fundamentals of Library Supervision (Chicago: American Library Association, 2010), 47.

29. Lynch and Smith, "The Changing Nature of Work in Academic Libraries"; Wang, Tang, and Knight, "Contemporary Development of Academic Reference Librarianship."

30. Joseph R. Matthews, Library Assessment in Higher Education (Westport, Conn.: Libraries 
Unlimited, 2007); Gail Munde and Kenneth E. Marks, Surviving the Future: Academic Libraries, Quality, and Assessment (London: Chando, 2009); Thomas P. Mackey and Trudi Jacobson, Collaborative Information Literacy Assessments: Strategies for Evaluating Teaching and Learning (New York: Neal-Schuman, 2010).

31. Martha Kyrillidou, Steve Hiller, and Jim Self, "2010 Library Assessment Conference: Reflections from the Conference Cochairs," The Library Quarterly 81, no. 1 (2011): 3-4.

32. Matthews, Library Assessment in Higher Education, 2.

33. Jeanie M. Welch, "Loosening the Ties That Bind: Academic Librarians and Tenure," College \& Research Libraries 67, no. 2 (2006): 171.

34. Hong Xu, "The Impact of Automation on Job Requirements and Qualifications for Catalogers and Reference Librarians in Academic Libraries," Library Resources \& Technical Services 40, no. 1 (1996): 29.

35. Applegate, "Job Ads, Jobs, and Researchers," 168.

36. Wang, Tang, and Knight, "Contemporary Development of Academic Reference Librarianship," 493.

37. Mark Winston and Gretchen Ebeler Hazlin, "Leadership Competencies in Library and Information Science: Marketing as a Component of LIS Curricula," Journal of Education for Library and Information Science 44, no. 2 (2003).

38. Claudene Sproles, Anna Marie Johnson, and Leslie Farison, "What the Teachers Are Teaching: How MLIS Programs Are Preparing Academic Librarians for Instructional Roles," Journal of Education for Library and Information Science 49, no. 3 (2008).

39. Joanne Oud, "Adjusting to the Workplace: Transitions Faced by New Academic Librarians," College \& Research Libraries 69, no. 3 (2008).

40. Oud, "Adjusting to the Workplace," 263.
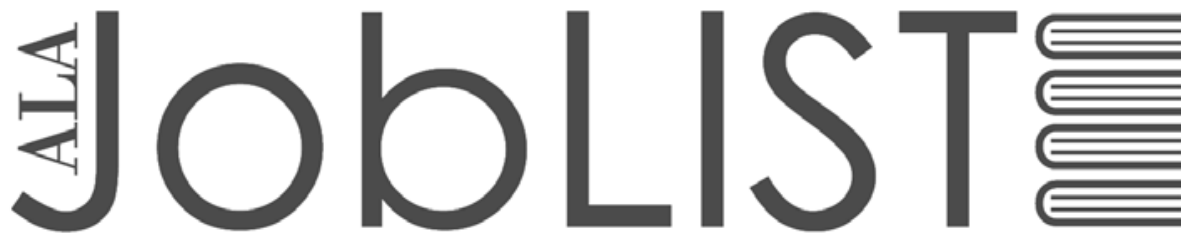

The \#1 source for jobs in Library and Information Science and Technology

\section{WHERE JOB SEEKERS AND EMPLOYERS GET RESULTS}

\section{JOB SEEKERS}

Search and sort hundreds

of job ads by position type,

employer, location, and more

\section{EMPLOYERS}

Strengthen your candidate pool-

ALA reaches the most engaged professionals and students

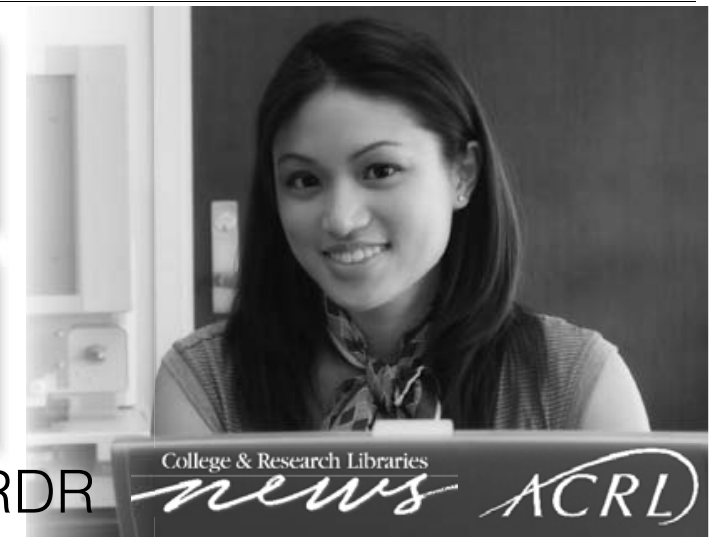

\section{ALA libriaries HRDR new
joblist.ala.org}

